\title{
Identification of cytotoxic T cells and their T cell receptor sequences targeting COVID-19 using MHC class I-binding peptides
}

\author{
Tetsuro Hikichi $^{1 凶}$, Michiko Sakamoto ${ }^{1}$, Makiko Harada ${ }^{1}$, Maki Saito ${ }^{1}$, Yuka Yamane ${ }^{1}$, Kimihisa Tokumura ${ }^{1}$ and Yusuke Nakamura $^{2}$
}

(c) The Author(s) 2022

Since severe acute respiratory syndrome coronavirus 2 (SARS-CoV-2, COVID-19) was first reported in China in December 2019, various variants have been identified in different areas of the world such as United Kingdom (alpha), South Africa (beta and omicron), Brazil (gamma), and India (delta). Some of SARS-CoV-2 variants, each of which is characterized by a unique mutation(s) in spike protein, are concerned due to their high infectivity and the capability to escape from neutralizing antibodies elicited by vaccinations. To identify peptide epitopes that are derived from SARS-CoV-2 viral proteins and possibly induce CD8 ${ }^{+} \mathrm{T}^{\mathrm{c}}$ cell immunity, we investigated SARS-CoV-2-derived peptides that are likely to bind to major histocompatibility complex (MHC) class I molecules. We identified a total of 15 peptides that bind to human leukocyte antigen (HLA)-A*24:02, HLA-A*02:01, or HLA-A*02:06, and possibly induce cytotoxic T lymphocytes (CTLs); thirteen of them corresponded to ORF1ab polyprotein, one peptide to spike protein and the remaining one to membrane glycoprotein. $\mathrm{CD} 8^{+} \mathrm{T}$ cells that recognize these peptides were detected in peripheral blood samples in three individuals recovered from COVID-19 as well as non-infected individuals. Since most of these peptides are commonly conserved among other coronaviruses including SARS-CoV and/or MERS-CoV, these might be useful to maintain $T$ cell responses to coronaviruses that are pandemic at present and will become the future threat. We could define pairs of TRA and TRB sequences of nine CTL clones that recognize SARS-CoV-2-derived peptides. We might use these SARS-CoV-2-derived peptidereactive TCR sequences for investigating the history of SARS-CoV-2 infection.

Journal of Human Genetics (2022) 67:411-419; https://doi.org/10.1038/s10038-022-01013-4

\section{INTRODUCTION}

Severe acute respiratory syndrome coronavirus 2 (SARS-CoV-2) infection has become world-wide pandemic. Until December 21, 2021, 273 million people have been confirmed the infection to COVID-19 and more than 5 million died of this disease.

In addition to intensive screening of infected individuals with PCR and/or antigen tests and subsequent isolation of coronapositive individuals, worldwide vaccination is fundamentally essential to overcome the present pandemic situation. Randomized trials demonstrated that Pfizer/BioNTech BNT162b2 and Moderna mRNA-1273 vaccines encoding the SARS-CoV-2 spike protein had $\sim 95 \%$ protective ability against COVID-19 [1, 2]. Vaccine-elicited neutralizing antibodies inhibit the spike protein on SARS-CoV-2, which was originally reported in December 2019 in China, to attach to the host cells. While these vaccines against COVID-19 have been used widely, SARS-CoV-2 variants have continuously emerged in different areas of the world. Virus variants, alpha, beta, gamma, delta, and omicron, which were defined by a unique amino acid substitution(s) within the spike protein, were identified in the United Kingdom [3], South Africa $[4,5]$, Brazil [6], and India [7], respectively. Neutralizing activity against these SARS-CoV-2 variants tends to decrease as compared to that against the original reference strain in individuals who received vaccination [8-12]; therefore, a novel vaccine(s) that is not affected by mutations in the virus genome is required for the fight against SARS-CoV-2.

Although most of the studies have focused on the neutralizing antibodies against the spike protein, we here describe induction of $\mathrm{CD}^{+} \mathrm{T}$ cells that are expected to play crucial roles in virus clearance through killing of virus-infected cells. In fact, in SARSCoV-2 infections, the presence of $\mathrm{CD}^{+} \mathrm{T}$ cells responding to SARS-CoV-2-derived peptides was shown to be associated with better clinical outcomes [13-15]. CD8 ${ }^{+}$T cells in COVID-19recovered individuals could recognize not only spike proteinderived peptides but also other viral proteins including nucleocapsid phosphoprotein, membrane glycoprotein, and ORFsderived peptides [16-18]. In previous studies, severe acute respiratory syndrome coronavirus (SARS-CoV)-specific memory $\mathrm{T}$ cells were detected in blood samples of SARS-recovered individuals after $6-11$ years of the initial infection $[19,20]$. T cell responses against the nucleocapsid phosphoprotein of SARS-CoV were maintained in individuals with the history of SARS-CoV

\footnotetext{
OncoTherapy Science, Inc, Kawasaki, Kanagawa, Japan. ${ }^{2}$ Cancer Precision Medicine Center, Japanese Foundation for Cancer Research, Tokyo, Japan.

email: t-hikichi@oncotherapy.co.jp
}

Received: 24 November 2021 Revised: 21 December 2021 Accepted: 3 January 2022

Published online: 2 February 2022 
412

infection 17 years after the outbreak of SARS in 2003 and these memory T cells showed cross-reactivity to SARS-CoV-2 [17]. These data indicate that memory $T$ cells may also critically contribute to long-term protection from COVID-19.

In a present study, we demonstrate major histocompatibility complex (MHC) class l-binding epitope peptides derived from SARS-CoV-2 viral proteins to enhance antiviral $\mathrm{CD}^{+}{ }^{+} \mathrm{T}$ cells immunity. To characterize cytotoxic T lymphocytes (CTLs) that recognize SARS-CoV-2-derived peptides and play a central role in $T$ cell immunity, we further conduct $T$ cell receptor (TCR) analysis for peptide-specific CTLs. The results should provide useful information for $\mathrm{T}$ cell responses against SARS-CoV-2 infection.

\section{MATERIALS AND METHODS \\ Samples}

The study protocol was approved by the Institutional Review Board of OncoTherapy Science and the written informed consent was obtained from each of peripheral blood mononuclear cells (PBMCs) donors.

\section{PBMCs}

For in vitro CTL induction, human leukocyte antigen (HLA)-A*24:02-positive PBMCs were isolated from blood of healthy volunteers by density gradient centrifugation using Ficoll-Paque PLUS (Cytiva) according to an industrial instruction manual. HLA-A*02:01- or HLA-A*02:06-positive PBMCs were purchased from Cellular Technology Limited (Cleveland, $\mathrm{OH}$ ). For tetramer staining, HLA-A*24:02-positive PBMCs derived from COVID-19-recovered individuals with a prior positive SARS-CoV-2 PCR test were purchased from Precision For Medicine (Bethesda, MD). Healthy individuals-derived PBMCs that were collected before the SARS-CoV-2 pandemic (March 2018-May 2019) were purchased from Cellular Technology Limited.

\section{Cell lines}

TISI cells (HLA-A*24:02/-, lymphoblastoid cell) were purchased from the IHWG Cell and Gene Bank (Seattle, WA). T2 (HLA-A*02:01/-, lymphoblast), Jiyoye (HLA-A32, Burkitt's lymphoma), and EB-3 (HLA-A3/Aw32, Burkitt's lymphoma) cells were purchased from American Type Culture Collection (Manassas, VA). HEV0011 (HLA-A*02:06/-, B lymphocytes) cells were purchased from RIKEN Bioresource Research Center (Tsukuba, Japan). All cells were cultured in RPMI1640 media (GIBCO) supplemented with $10 \%$ fetal bovine serum (GIBCO) and 1\% antibiotic solution (Wako).

\section{Peptides}

SARS-CoV-2-derived 9-mer and 10-mer peptides were synthesized by Cosmo Bio Co., Ltd. (Otaru, Japan). The purity $(>90 \%)$ and the sequences of peptides were confirmed by analytical HPLC and a mass spectrometry analysis. Peptides were dissolved in dimethyl sulfoxide at $20 \mathrm{mg} / \mathrm{mL}$ and stored at $-80^{\circ} \mathrm{C}$ until the use for in vitro CTL induction, an IFN- $\gamma$ enzymelinked immunospot (ELISPOT) assay and an IFN- $\gamma$ enzyme-linked immunosorbent assay (ELISA).

\section{in vitro CTL induction}

Monocyte-derived dendritic cells (DCs) were generated from PBMCs. Monocytes were isolated from PBMCs by adherence to a plastic tissue culture dish (Becton Dickinson) and cultured in the presence of $1000 \mathrm{IU} / \mathrm{mL}$ of granulocyte-macrophage colony-stimulating factor (R\&D System) and $1000 \mathrm{IU} / \mathrm{mL}$ of interleukin (IL)-4 (R\&D System) in AIM-V medium (Invitrogen) supplemented with 2\% human AB serum (SIGMA) for 7 days. On day 5, OK-432 (Chugai Pharmaceutical) was added in the culture medium to induce the maturation of DCs (final concentration: $0.1 \mathrm{KE} / \mathrm{mL}$ ). Autologous $\mathrm{CD}^{+} \mathrm{T}$ cells $\left(3.0 \times 10^{5}\right.$ cells) purified from PBMCs with CD8Positive Isolation Kit (Dynal) were cultured with DCs $\left(1.5 \times 10^{4}\right.$ cells) with $20 \mu \mathrm{g} / \mathrm{mL}$ of each peptide in AIM-V medium containing $2 \%$ human $A B$ serum, $10 \mathrm{ng} / \mathrm{mL}$ of IL-7 (R\&D System), and $30 \mathrm{ng} / \mathrm{mL}$ of IL-21 (Cell Genix). After 3 days of the culture, $C D 8^{+}$T cells were restimulated with DCs and $20 \mu \mathrm{g} / \mathrm{mL}$ of each peptide. DCs were prepared by the same procedure described above. At day 7 of the culture, $\mathrm{CD}^{+} \mathrm{T}$ cells were further stimulated with $48 \mathrm{IU} / \mathrm{mL}$ of IL-2 (Novartis), $5 \mathrm{ng} / \mathrm{mL}$ of IL-7 (Novoprotein), and $5 \mathrm{ng} / \mathrm{mL}$ of IL-15 (Novoprotein) in AIM-V medium supplemented with
$2 \%$ human $A B$ serum. At day 11 of the culture, $C D 8^{+} \mathrm{T}$ cell responses were examined by an IFN- $\gamma$ ELISPOT assay.

\section{IFN- $\gamma$ ELISPOT assay}

The human IFN- $\gamma$ ELISPOT kit and AEC substrate set (BD Biosciences) were used to analyze $\mathrm{CD}^{+} \mathrm{T}$ cell responses to SARS-CoV-2-derived peptides. The ELISPOT assay was performed according to the industrial instruction manual. Briefly, TISI, T2, or HEV0011 cells were used as stimulator cells. These cells were cultured with or without $20 \mu \mathrm{g} / \mathrm{mL}$ of peptide overnight at $37^{\circ} \mathrm{C}$. To analyze $\mathrm{CD} 8^{+} \mathrm{T}$ cell responses, $500 \mu \mathrm{L}$ of supernatant was removed from each well of culture plates for in vitro CTL induction. Subsequently $100 \mu \mathrm{L}$ of cell suspensions and stimulator cells $\left(2 \times 10^{4}\right.$ cells) with or without each peptide were co-cultured in 96-well plates coated with anti-IFN- $\gamma$ antibody. After $16-18 \mathrm{~h}$ incubation, IFN- $\gamma$ spots were detected and counted using ImmunoSpot S6 analyzer (Cellular Technology Limited).

\section{Limiting dilution}

$\mathrm{CD}^{+} \mathrm{T}$ cells were diluted to 0.5 cell or 10 cells per well in 96-well roundbottom plates (Corning) and cultured with feeder cells in AIM-V medium containing $5 \%$ human $A B$ serum, $30 \mathrm{ng} / \mathrm{mL}$ of anti-CD3 monoclonal antibody (clone UCHT1; BD Biosciences), and $150 \mathrm{IU} / \mathrm{mL}$ of IL-2. Jiyoye and EB-3 cells $\left(1 \times 10^{4}\right.$ cells each) were used as feeder cells after treating with $30 \mu \mathrm{g} / \mathrm{mL}$ of Mitomycin C (MEDAC) at $37^{\circ} \mathrm{C}$ for $30 \mathrm{~min}$. After 10 days of the culture, IL-2 was added to each well (final concentration: $150 \mathrm{IU} / \mathrm{mL}$ ). After additional 4 days of the culture, IFN- $\gamma$ ELISPOT was performed for screening $\mathrm{CD}^{+} \mathrm{T}$ cell responses against each peptide.

\section{CTL expansion culture}

CTLs that showed positive reactivity in the IFN- $\gamma$ ELISPOT assay after limiting dilution were expanded. They were cultured with feeder cells in AIM-V medium containing $5 \%$ human AB serum and $40 \mathrm{ng} / \mathrm{mL}$ of anti-CD3 monoclonal antibody. Jiyoye and EB-3 cells $\left(5 \times 10^{6}\right.$ cells each) were used as feeder cells after treating with $30 \mu \mathrm{g} / \mathrm{mL}$ of Mitomycin $\mathrm{C}$ at $37^{\circ} \mathrm{C}$ for 30 $\mathrm{min}$. The half volume of culture medium was exchanged with fresh AIM-V containing $5 \%$ human $\mathrm{AB}$ serum and $72 \mathrm{IU} / \mathrm{mL}$ of IL-2 every 3 or 4 days. After 14 days of the culture, IFN- $\gamma$ secretion from CTLs was measured by ELISA.

\section{IFN- $\boldsymbol{\nu}$ ELISA}

ELISA were performed using IFN- $\gamma$ ELISA kit (BD Biosciences) according to the industrial instruction manual. Briefly, CTLs (Responders) and TISI, T2, or HEV0011 cells (Stimulators) with or without each peptide were co-cultured in $200 \mu \mathrm{L}$ of AIM-V medium supplemented with $5 \%$ human $A B$ serum at several ratio of Responders to Stimulators (R/S ratio). Responders at $5 \times 10^{4}$, $2.5 \times 10^{4}, 1.25 \times 10^{4}, 0.625 \times 10^{4}$, or $0.3125 \times 10^{4}$ cells/well concentration were plated in 96 -well round-bottom plates together with $1 \times 10^{4}$ Stimulators. After $16-18 \mathrm{~h}$ of the incubation, supernatants were collected for measurement of IFN- $\gamma$. IFN- $\gamma$ production was calculated as $\mathrm{pg} / \mathrm{mL}$ using a standard curve.

\section{TCR sequencing}

Total RNAs were extracted from peptide-specific CTL clones using RNeasy mini kit (QIAGEN). CDNAs were synthesized using SMARTScribe Reverse Transcriptase (Clontech). SARS-CoV-2-derived peptides-reactive TCR sequences were identified by Sanger sequencing. TCRa CDNA was amplified by PCR using a common forward primer for adaptor (5'-GTCTCGT GGGCTCGGAGATGTGTATAAGAGACAGTATCAACGCAGAGTGGCCAT-3') and a reverse primer specific for the constant region (5'-TCGTCGGCAGCGTCAGATGT GTATAAGAGACAGDBDHHCAGGGTCAGGGTTCTGGATA-3'). Sanger sequencing was performed using M13 forward primer (5'-TGTAAAACGACGGCC AGTG-3') and M13 reverse primer (5'-CAGGAAACAGCTATGACCAT-3') after TA cloning. TCR $\beta$ CDNA was amplified using a common forward primer for adaptor and a reverse primer specific for the constant region (5'-TC GTCGGCAGCGTCAGATGTGTATAAGAGACAGDVHDVTCTGATGGCTCAAACACA GC-3') [21]

\section{in vitro stimulation}

PBMCs $\left(5 \times 10^{5}\right.$ cells $\left./ \mathrm{mL}\right)$ obtained from COVID-19-recovered individuals or healthy individuals without the history of SARS-CoV-2 infection were 
Software: NetMHC 4.0 Server

HLA: HLA-A*24:02, HLA-A*02:01 and HLA-A*02:06

Target protein: Spike, Envelope, Membrane,

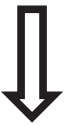

Nucleocapsid, ORF1ab, ORF3a,

ORF6, ORF7a, ORF8 and ORF10

\section{Selection \\ Length: 9-mer and 10-mer \\ Affinity: $<120 \mathrm{nM}$

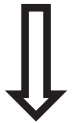 \\ Homology: SARS-CoV and MERS-CoV}

in vitro CTL induction

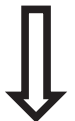

Identification

CTLs response to

(IFN-y secretion)

Fig. 1 Flowchart for identifying MHC class I-binding peptidescandidates derived from SARS-CoV-2 viral proteins

stimulated with $10 \mu \mathrm{g} / \mathrm{mL}$ of each peptide in mixture of $50 \%$ AIM-V and $50 \%$ RPMI1640 medium supplemented with $10 \%$ fetal bovine serum. After 4 days of the stimulation, PBMCs were restimulated with $10 \mu \mathrm{g} / \mathrm{mL}$ of each peptide. PBMCs were cultured for 12 days adding $120 \mathrm{IU} / \mathrm{mL}$ of IL-2 on days 5,7 , and 10.

\section{Preparation of tetramers}

SARS-CoV-2-derived peptides-loaded MHC class I (pMHCl) tetramers were generated by QuickSwitch ${ }^{\text {TM }}$ Quant HLA-A*24:02 Tetramer Kit-PE (MBL International Corporation) according to an industrial instruction manual [22]. Briefly, $50 \mu \mathrm{L}$ of tetramer folded with an irrelevant exchangeable peptide at $50 \mu \mathrm{g} / \mathrm{mL}$ was mixed with $1 \mu \mathrm{L}$ of peptide at $1 \mathrm{mg} / \mathrm{mL}$ and $1 \mu \mathrm{L}$ of Peptide Exchange Factor for $4 \mathrm{~h}$ at room temperature. Rate of peptide exchange was quantitated by flow cytometry. When irrelevant exchangeable peptides were exchanged for SARS-CoV-2-derived peptides at a rate of more than $75 \%$, tetramers were used for staining PBMCs.

\section{Tetramer staining}

After in vitro stimulation, PBMCs were incubated with phycoerythrin (PE)conjugated tetramer on ice for $30 \mathrm{~min}$. Following wash in Dulbecco's phosphate-buffered saline (DPBS, GIBCO) with $0.5 \%$ bovine serum albumin (BSA, Iwai Chemicals), the cells were stained with fluorescein isothiocyanate-conjugated anti-human CD8 antibody (clone RPA-T8, BD Biosciences), allophycocyanin-conjugated anti-human CD3 antibody (clone UCHT1, BD Biosciences), and phycoerythrin-Cy7 (PE-Cy7)-conjugated antihuman CD4 antibody (clone RPA-T4, BD Biosciences) on ice for $20 \mathrm{~min}$. The cells were washed in DPBS with $0.5 \%$ BSA and then stained with DPBS containing $0.1 \mu \mathrm{g} / \mathrm{mL}$ 4',6-diamidino-2-phenylindole (DAPI, BD Biosciences). $\mathrm{CD}^{+}{ }^{\mathrm{T}}$ cells that bound to $\mathrm{pMHCl}$ tetramer were identified using SH800 (Sony Biotechnology). PBMCs were treated with $450 \mathrm{nM}$ dasatinib (Cayman Chemical) for inhibiting TCR downregulation from surface of T cells before tetramer staining [23].
RESULTS

Prediction and selection of MHC class I-binding peptides derived from SARS-CoV-2 viral proteins

The workflow for screening of SARS-CoV-2-derived MHC class I-binding peptides is shown in Fig. 1. Firstly, we predicted MHC class I-binding peptide epitopes derived from SARS-CoV-2 viral proteins including the structural proteins (spike, envelope, membrane glycoprotein, and nucleocapsid phosphoprotein) as well as the non-structural proteins (ORF1ab, ORF3a, ORF6, ORF7a, ORF8, and ORF10) as previously described [24]. Peptide-MHC affinity was calculated using NetMHC 4.0 server $[25,26]$. We targeted HLA-A*24:02, HLA-A*02:01, and HLA-A*02:06 because they covered a large proportion (more than $80 \%$ ) of Japanese populations [27].

We focused peptide epitopes that were conserved in either or both of SARS-CoV and Middle East respiratory syndrome coronavirus (MERS-CoV) to develop common and universal vaccines that can be possibly effective for newly arising coronaviruses in the future.

We firstly selected 14 peptides (P01-P14) that were expected to bind to an HLA-A ${ }^{*} 24: 02$ molecule (predicted MHC affinity of $<120$ $\mathrm{nM}$ ). Two of the 14 peptides (P06 and P11) were common among coronaviruses including SARS-CoV and MERS-CoV. The remaining 12 peptides were conserved in SARS-CoV. We also selected 15 peptides (P15-P28 and P08) that were expected to bind to both HLA-A*02:01 and HLA-A*02:06 molecules (predicted MHC affinity of $<120 \mathrm{nM}$ ). They are commonly shared with SARS-CoV. All candidate peptides are shown in Table 1.

\section{Identification of MHC class I-binding peptides derived from} SARS-CoV-2 (HLA-A*24:02)

To examined CTL induction by peptides, we first used HLA$A^{*}$ 24:02-positive PBMCs isolated from two healthy donors. Briefly, autologous $\mathrm{CD}^{+} \mathrm{T}$ cells and monocyte-derived $\mathrm{DCs}$ were prepared from PBMCs. CD8 ${ }^{+} \mathrm{T}$ cells were cultured with $\mathrm{DCs}$ pulsed with each peptide. After 11 days of stimulation by each peptide, $C D 8^{+} T$ cells were cultured overnight with HLA-A*24:02positive TISI cells that were pulsed with or without each peptide. $\mathrm{CD}^{+} \mathrm{T}$ cell responses to each peptide were analyzed by an IFN- $\gamma$ ELISPOT assay. They were considered as positive when IFN- $\gamma$ spot counts were 1.5 times or higher, compared with the peptidenegative control. Positive reactivities were detected in 9 of the 14 peptides examined (Fig. 2A).

We subsequently conducted limiting dilution to establish peptide-specific CTL clones from the initial $C D 8^{+}$T cell populations that showed positive reactivity in the IFN- $\gamma$ ELISPOT assay. $\mathrm{CD}^{+} \mathrm{T}$ cells were diluted to 10 cells per well in 96-well roundbottom plates. After 14 days of the culture, peptide-specific CTLs were screened using an IFN- $\gamma$ ELISPOT assay. CTL responses to each peptide were examined by an IFN- $\gamma$ ELISA following the cell expansion. Peptide-specific IFN- $\gamma$ secretion against eight peptides were observed when TISI cells were used as stimulator cells for presenting individual peptides (Fig. 2B). This indicates that these peptides were likely to be presented on the HLA-A*24:02 molecule and recognized by TCRs on CTLs.

\section{Identification of MHC class I-binding peptides derived from SARS-CoV-2 (HLA-A*02:01 and HLA-A*02:06)}

We similarly investigated CTL induction for 15 candidate epitopes (P15-P28 and P08 listed in Table 1) using HLA-A*02:01-positive donor-derived PBMCs. $\mathrm{CD} 8^{+}$T cells were cultured overnight with HLA-A*02:01-positive T2 cells pulsed with or without each peptide. Positive reactivity was detected by an IFN- $\gamma$ ELISPOT assay for 13 of the 15 peptides examined (Fig. 3A). Then, we performed limiting dilution and further confirmed the peptide-specific IFN- $\gamma$ secretion in expanded T cells stimulated with 8 of the 13 peptides (Fig. 3B). Since HLA-A*02:01 and HLA-A*02:06 have an only one 
Table 1. SARS-CoV-2-derived candidate peptides bind MHC class I (HLA-A*24:02, HLA-A*02:01, or HLA-A*02:06)

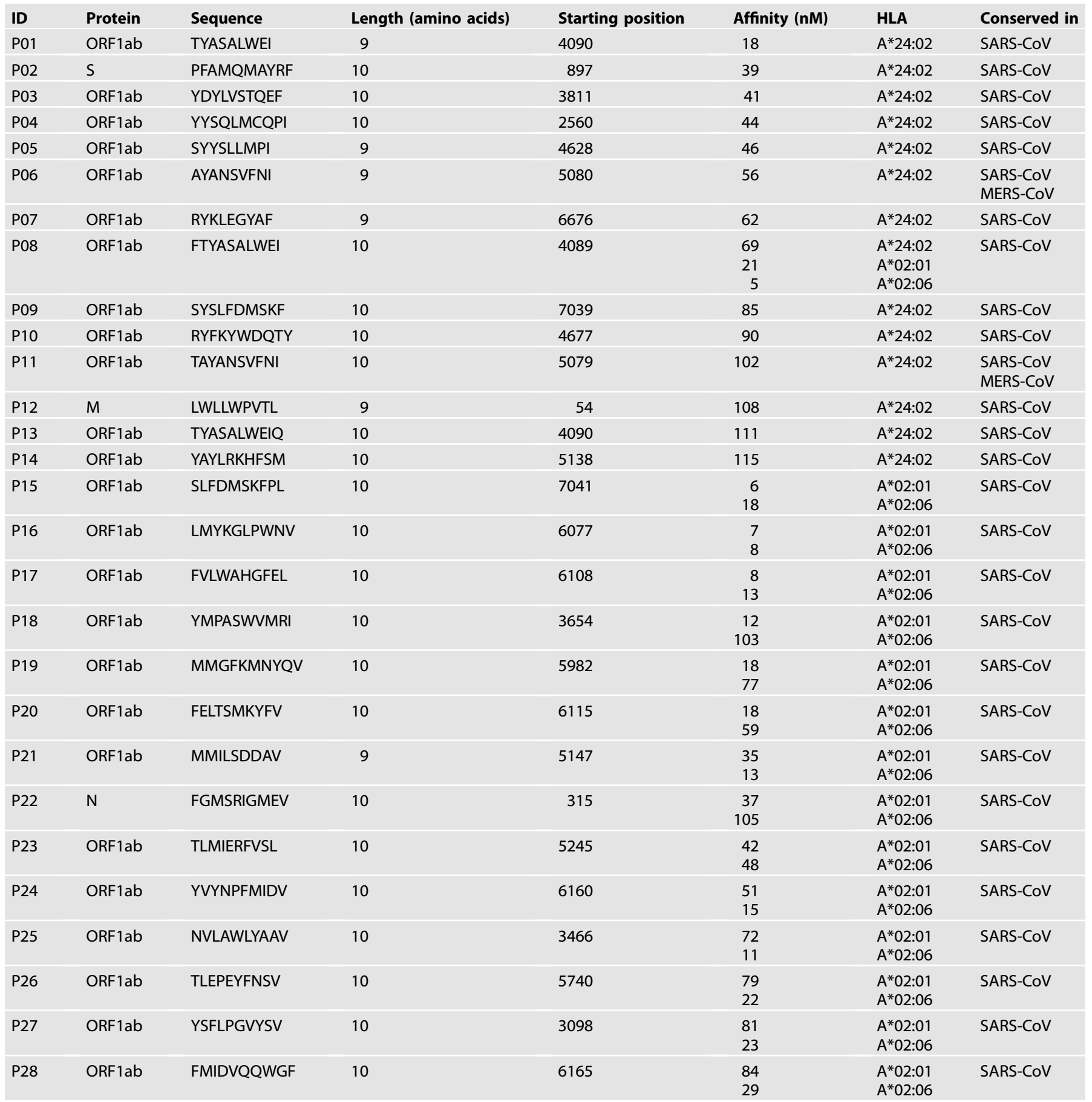

$S$ spike protein, $M$ membrane glycoprotein, $N$ nucleocapsid phosphoprotein

amino acid substitution (F9Y) in a region of the peptide binding groove $[28,29]$, it has been indicated that some peptides bind to both HLA-A*02:01 and HLA-A*02:06 molecules [30, 31]. Hence, we investigated the cross-reactivity of these eight peptides to an HLA$A^{*} 02: 06$ molecule using $H L A-A^{*} 02: 06-$ positive donor-derived PBMCs. As we expected, we found the positive reactivity of seven peptides in an IFN- $\gamma$ ELISPOT assay (Fig. S1A) as well as the peptide-specific IFN- $\gamma$ secretions in an ELISA (Fig. S1B).

\section{TCR sequences recognizing SARS-CoV-2-derived peptides}

SARS-CoV-2-derived peptide-specific CTL clones were established from $\mathrm{CD}^{+} \mathrm{T}$ cell population that showed positive reactivity to each of the peptides after in vitro CTL induction (Fig. S2A, B). Then DNA sequences of pairs of TCRa and TCR $\beta$ were examined using established CTL clones. We show pairs of TRA and TRB sequences that were likely to recognize SARS-CoV-2-derived peptides in Table 2. 
A

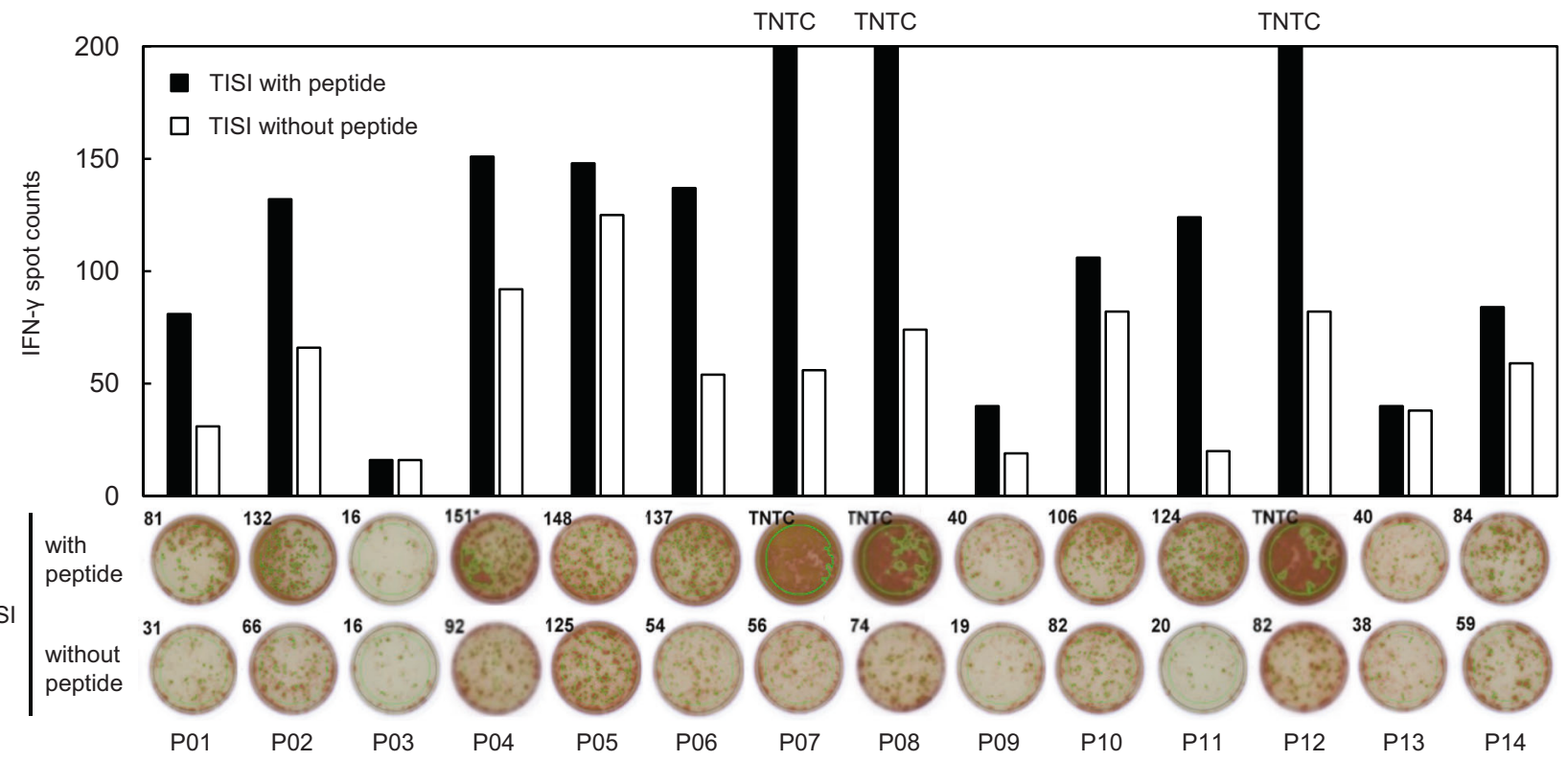

B
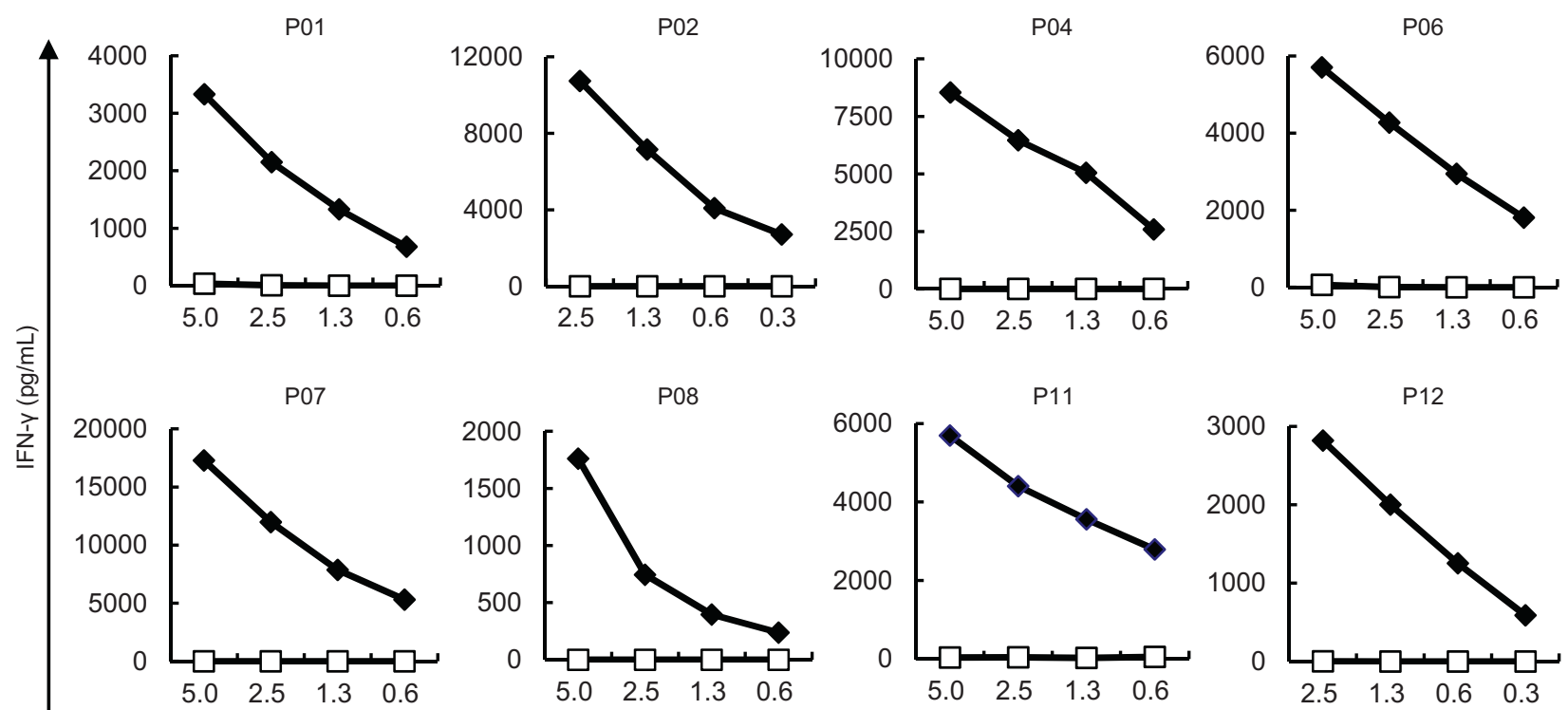

$\mathrm{R} / \mathrm{S}$ ratio

Fig. 2 Identification of HLA-A*24:02-binding peptides derived from SARS-CoV-2. A IFN- $\gamma$ ELISPOT assay was performed after in vitro CTL induction. $C D 8^{+}$T cells and HLA-A*24:02-positive TISI cells pulsed with each peptide were co-cultured overnight. TISI cells without the peptide were used as negative control. Bars represent the number of IFN- $\gamma$ spots. CD8 ${ }^{+} \mathrm{T}$ cell responses were judged as positive when the number of IFN- $\gamma$ spots were 1.5 times or higher than the negative control (P01, P02, P04, P06, P07, P08, P09, P11, and P12). Representative positive activities to P02, P06, P08, and P12 observed in PBMCs from two donors are shown. No positive response was observed for P03, P05, P10, P13, and P14 in two PBMCs. Spot counts higher than 200 are demonstrated as "too numerous to count (TNTC)". B To confirm the response of CTLs to SARS-CoV-2-derived peptides, IFN- $\gamma$ ELISA was performed. CTLs (Responders) were co-cultured overnight with TISI cells (Stimulators) pulsed with or without the peptide at the indicated ratio of Responders to Stimulators (R/S ratio). IFN- $\gamma$ secretion was measured by ELISA. CTLs that revealed the peptide-specific IFN- $\gamma$ secretion for eight peptides are shown. Similar results were obtained in independent experiments using three CTLs in the respective peptides

\section{Detection of SARS-CoV-2-derived peptides-reactive CD8 ${ }^{+}$ $T$ cells in PBMCs}

We analyzed HLA-A*24:02-positive PBMCs from individuals who recovered from COVID-19 $(n=3)$ and healthy individuals without any evident SARS-CoV-2 infection $(n=3)$ to examine $\mathrm{CD}^{+}{ }^{+} \mathrm{T}$ cells that might recognize $\mathrm{MHC}$ class I-binding peptides we identified. After in vitro stimulation, PBMCs were stained with PE-conjugated $\mathrm{pMHCl}$ tetramers and analyzed by flow cytometry (Fig. 4A). $\mathrm{pMHCl}$ tetramer-binding $\mathrm{CD}^{+}{ }^{+} \mathrm{T}$ cells were detected from three individuals recovered from COVID-19 (Fig. 4B). It is notable that 
A
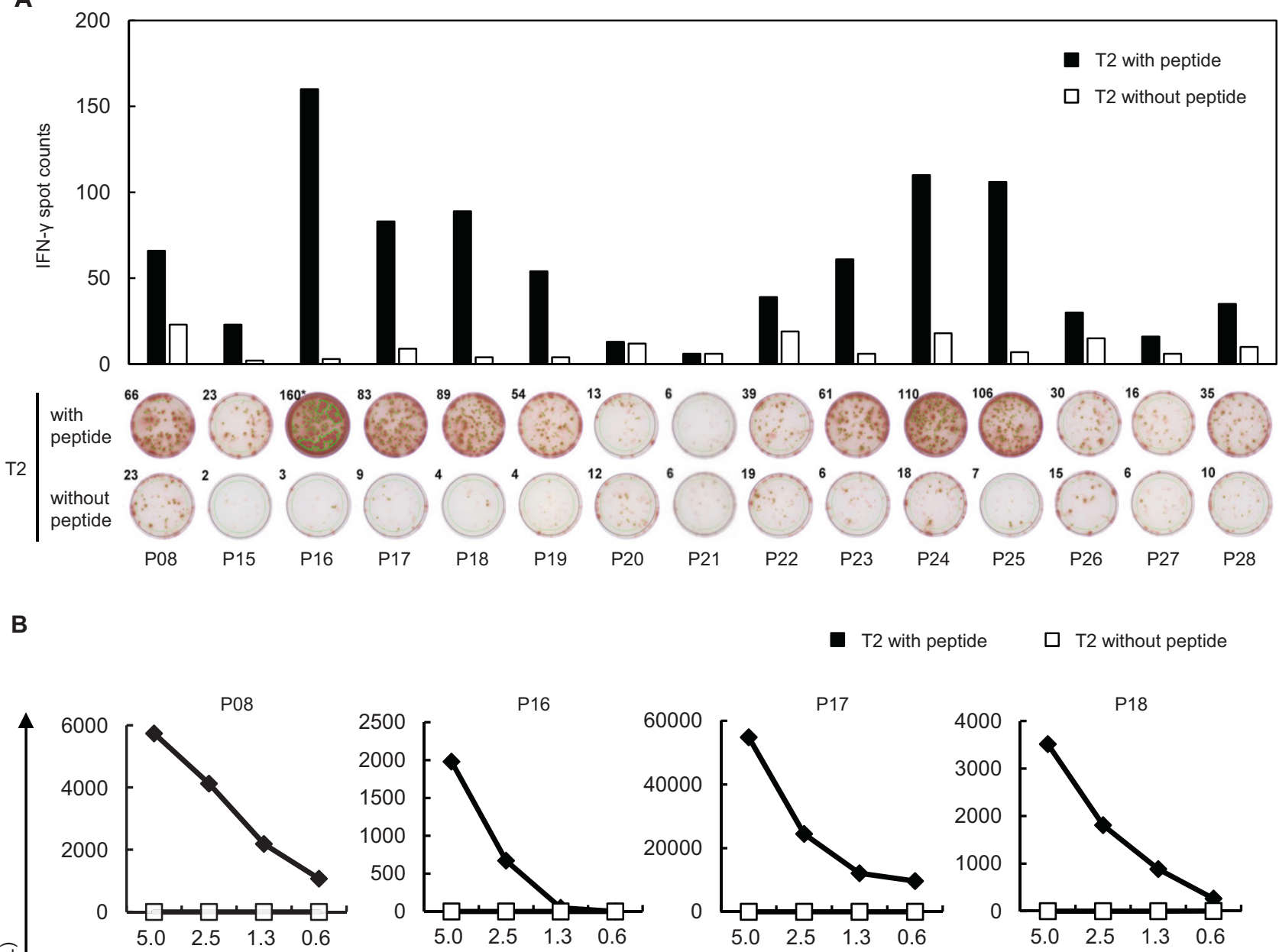

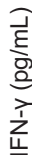
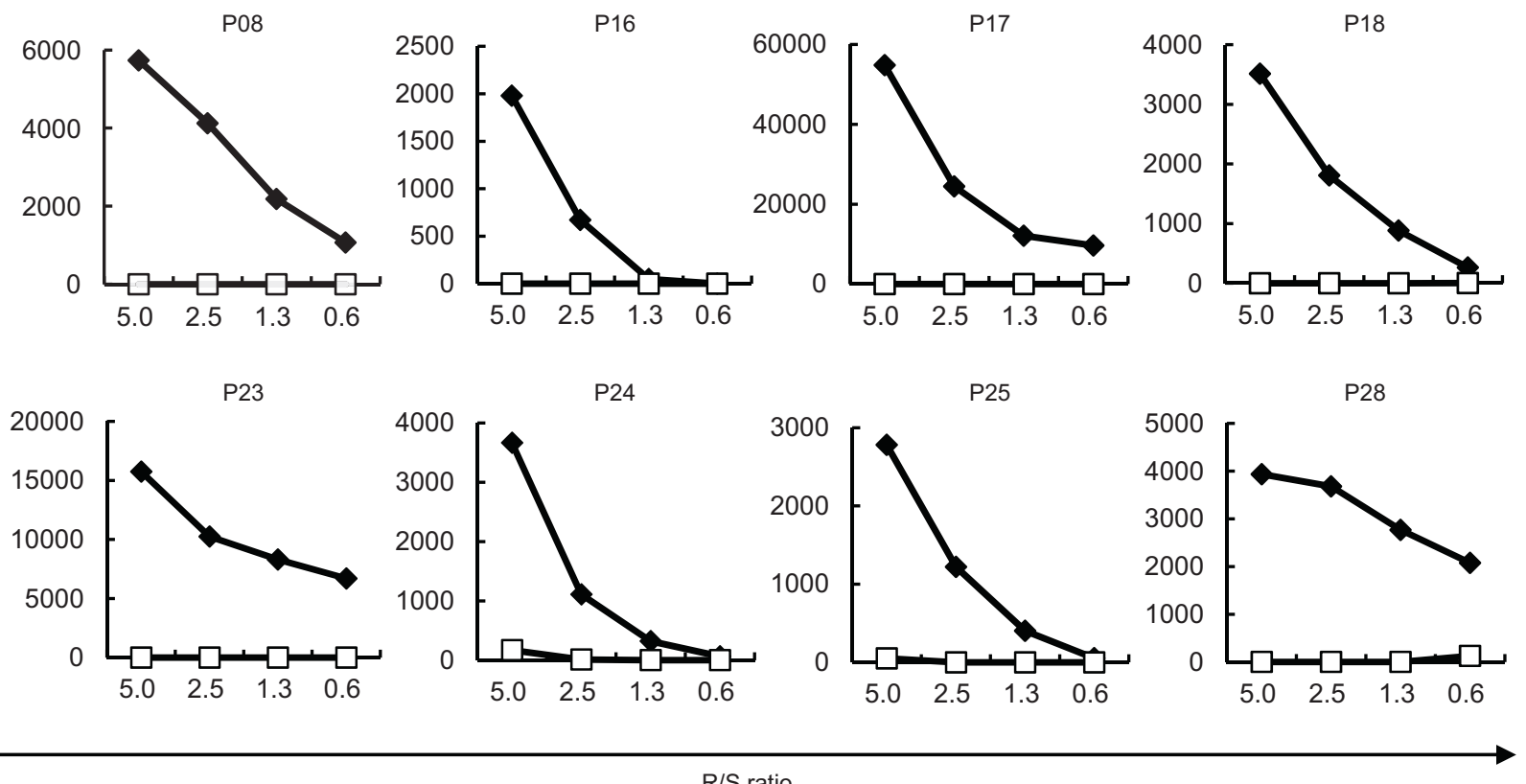

$\mathrm{R} / \mathrm{S}$ ratio

Fig. 3 Identification of HLA-A*02:01-binding peptides derived from SARS-CoV-2. A IFN- $\gamma$ ELISPOT assay was performed after in vitro CTL induction. $\mathrm{CD}^{+}$T cells and HLA-A*02:01-positive T2 cells pulsed with each peptide were co-cultured overnight. T2 cells without the peptide were used as negative control. Bars represent the number of IFN- $\gamma$ spots. CD8 ${ }^{+} \mathrm{T}$ cell responses were judged as positive when the number of IFN- $\gamma$ spots were 1.5 times or higher than the negative control. B To confirm the response of CTLs to SARS-CoV-2-derived peptides, IFN- $\gamma$ ELISA was performed. CTLs (Responders) were co-cultured overnight with T2 cells (Stimulators) pulsed with or without the peptide at the indicated ratio of Responders to Stimulators (R/S ratio). IFN- $\gamma$ secretion was measured by ELISA. CTLs that revealed the peptide-specific IFN- $\gamma$ secretion for eight peptides are shown. Similar results were obtained in independent experiments using three CTLs in the respective peptides

we found $\mathrm{CD}^{+} \mathrm{T}$ cells recognizing SARS-CoV-2-derived peptides (P04, P06, and P12), which are conserved in other coronaviruses (Table S1), in one non-infected healthy individual as well (Fig. 4C).

\section{Impact of SARS-CoV-2 omicron variant on MHC class I-binding peptides}

We investigated the influence of mutations found in SARS-CoV-2 omicron variant (BA.1), which is a new SARS-CoV-2 variant of concern and has been identified in 89 countries as of 16 th of
December, 2021, on 15 MHC class I-binding peptides identified in this study. We searched nonsynonymous substitutions and deletions in the GISAID database (https://www.gisaid.org) on 20th of December, 2021. We identified 132 mutations (76 mutations in ORF1ab polyprotein, 51 mutations in spike protein, and 5 mutations in membrane glycoprotein) in 9 or more $(>0.1 \%)$ of 8993 sequences of omicron variant. Only one mutation at position 5086 (F5086Y) in ORF1ab may affect immunogenicity of P06 and P11, but other peptide sequences are conserved in the 


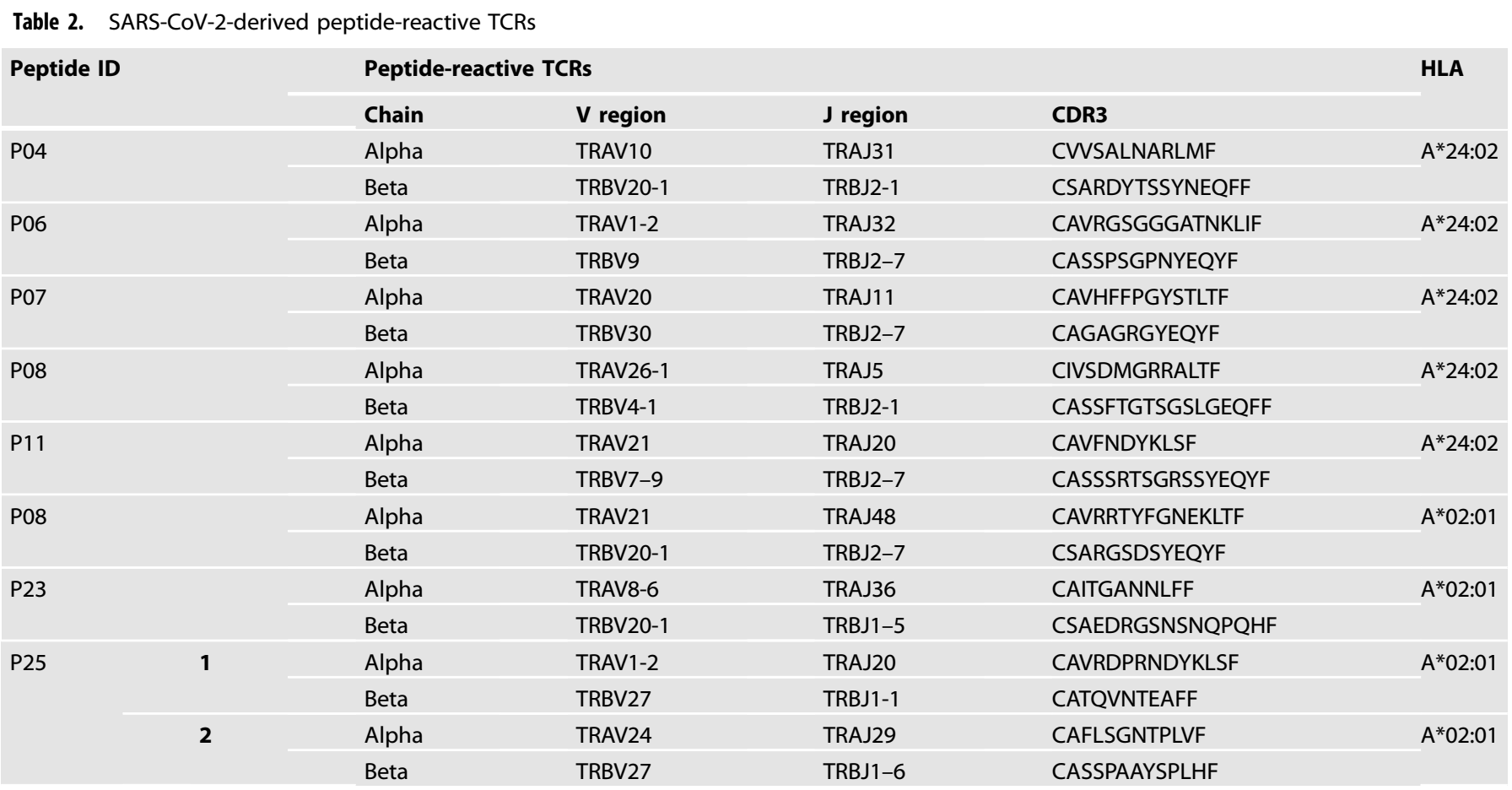

omicron variant (Table S2). This indicates that the peptides identified in this study may be used as a sort of universal peptides to induce CTLs against COVID-19 variants.

\section{DISCUSSION}

We screened 29 SARS-CoV-2-derived epitope peptides (14 peptides for HLA-A*24:02 and 15 peptides for HLA-A*02:01) that were predicted to bind to $\mathrm{MHC}$ class I molecules for activation of $\mathrm{CD}^{+} \mathrm{T}$ cells and found that eight peptides each for HLA-A*24:02 and HLA-A ${ }^{*}$ 02:01 could activate $C D 8^{+} T$ cells isolated from PBMCs. We subsequently established CTL clones and confirmed their immune reactivities against these peptides presented on the expected HLA molecules. Among the eight peptides that activated $\mathrm{CD}^{+} \mathrm{T}$ cells derived from HLA-A*02:01 donors, seven peptides also activated $\mathrm{CD} 8^{+} \mathrm{T}$ cells derived from $\mathrm{HLA}-\mathrm{A}^{*} 02: 06$-positive PBMCs. Interestingly, one peptide (P08) commonly induced CTLs derived from all of HLA-A*24:02-, HLA-A*02:01-, and HLA-A*02:06positive PBMCs. Hence, a total of 15 peptides were likely to be presented on MHC class I molecules and activated $\mathrm{CD}^{+} \mathrm{T}$ cells. These 15 peptides corresponded to parts of spike protein, membrane glycoprotein, or ORF1ab polyprotein (Fig. S3).

Variant SARS-CoV-2 strains, alpha, beta, gamma, delta, and omicron, which are now classified as variants of concern by World Health Organization, rapidly expanded worldwide and are still expanding in some countries. SARS-CoV-2 variants of concern appear to escape at some extent from vaccinations using mRNA encoding the spike protein because they have mutations in domains recognized by neutralizing antibodies. Since multiple peptides identified from spike protein, membrane glycoprotein, and ORF1ab polyprotein in this study are well conserved among coronavirus species, it is likely that these regions are essential for virus survival or expansion. Hence, $\mathrm{T}$ cells induced by these peptides reported here might be less affected by mutations that may additionally occur in various virus proteins. In fact, mutations found in the omicron variant have little effect on immunogenicity of these peptides at present although we need to further monitor the variant sequences.
We confirmed the presence of $\mathrm{CD}^{+} \mathrm{T}$ cells that recognize SARS-CoV-2-derived peptides (P01, P02, P07, P08, and P12) in HLA$A * 24: 02$-positive individuals recovered from COVID-19, indicating that $\mathrm{CD} 8^{+} \mathrm{T}$ cells were activated in vivo by coronavirus-derived peptides (possibly same as peptides identified in this study) presented on MHC class I molecules on antigen presenting cells including DCs in their body. It is notable that we found $C D 8^{+}$ $T$ cells that recognized SARS-CoV-2-derived peptides (P04, P06, and P12) in one SARS-CoV-2-non-infected healthy individual. Since these peptides are conserved among other human coronaviruses, the presence of $\mathrm{CD}^{+} \mathrm{T}$ cells reacting to these peptides may reflect previous infections with these viruses, or this individual might have experienced non-symptomatic COVID-19. Understanding the effect of pre-existing SARS-CoV-2-derived peptidereactive $\mathrm{CD}^{+} \mathrm{T}$ cells on non-symptomatic patients or prevention of COVID-19 should be important to consider the strategy for controlling pandemic or the future threat to newly arising coronaviruses.

Recently, one report indicated that a spike protein-derived polypeptide with adjuvant on nanoparticle, which was administrated by intramuscular route, successfully induced neutralizing antibodies and $\mathrm{CD}^{+} \mathrm{T}$ cell responses in rhesus macaques [32]. This report also supports the concept that SARS-CoV-2-derived epitope peptides might be a promising COVID-19 vaccine that would induce and maintain the T cell immunity against SARS-CoV2 that will continuously cause new mutations. In addition, we found no significant homology with peptides possibly derived from human proteins by the BLAST algorithm (https://blast.ncbi. nlm.nih.gov/Blast.cgi), suggesting there is little possibility that our peptides might cause unintended immune reactions, which are unfavorable to our health condition.

Furthermore, T-Detect COVID Test (Adaptive Biotechnologies), a next-generation TCR sequencing-based test, was approved by FDA for identifying the recent or prior SARS-CoV-2 infection. Our peptide-reactive TCR sequences might be useful to investigate SARS-CoV-2 infection history or monitor the effectiveness in vaccinated individuals. 


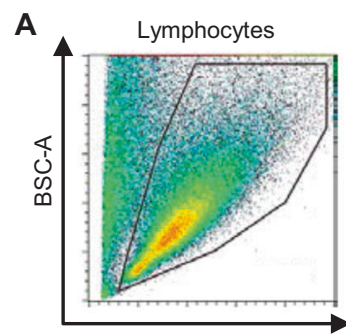

FSC-A

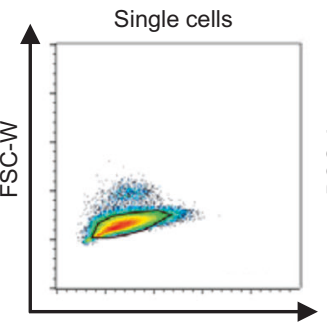

FSC-H

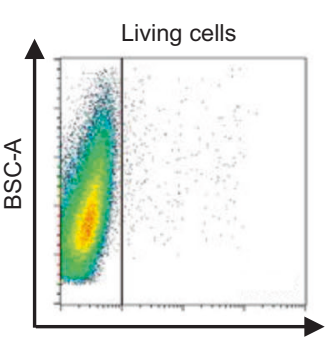

DAPI

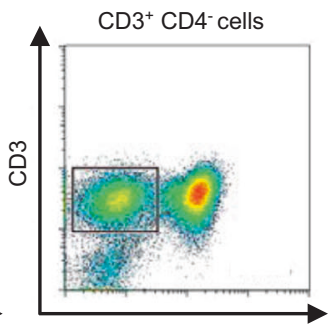

CD4

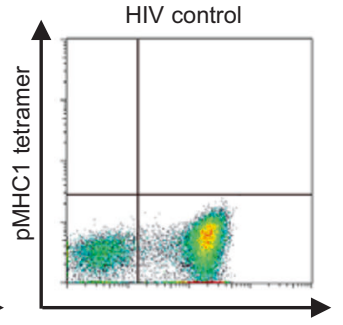

CD8

B COVID-19-recovered individuals 1
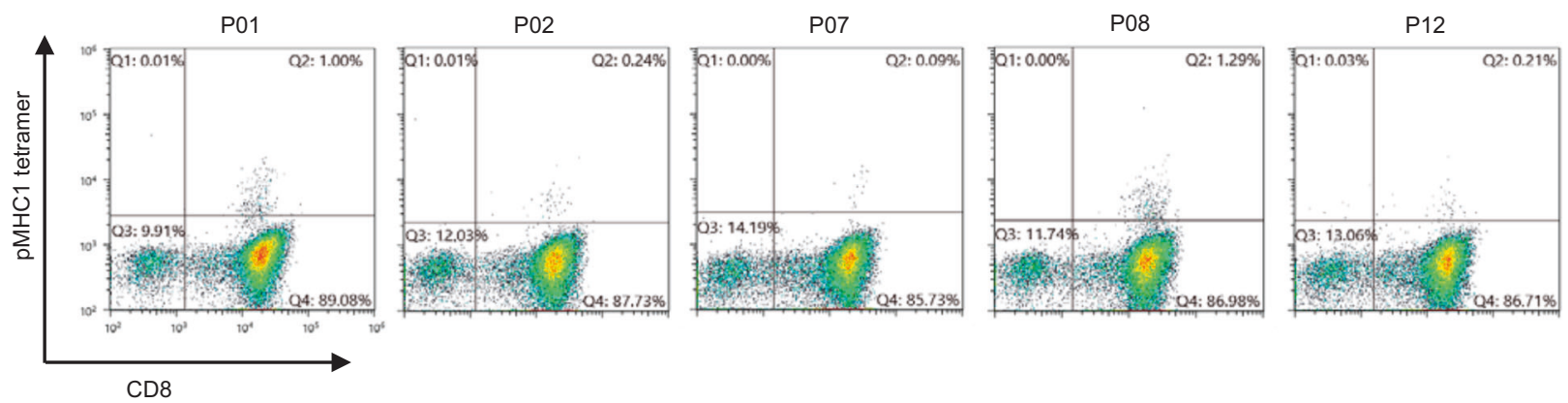

COVID-19-recovered individuals 2

COVID-19-recovered individuals 3
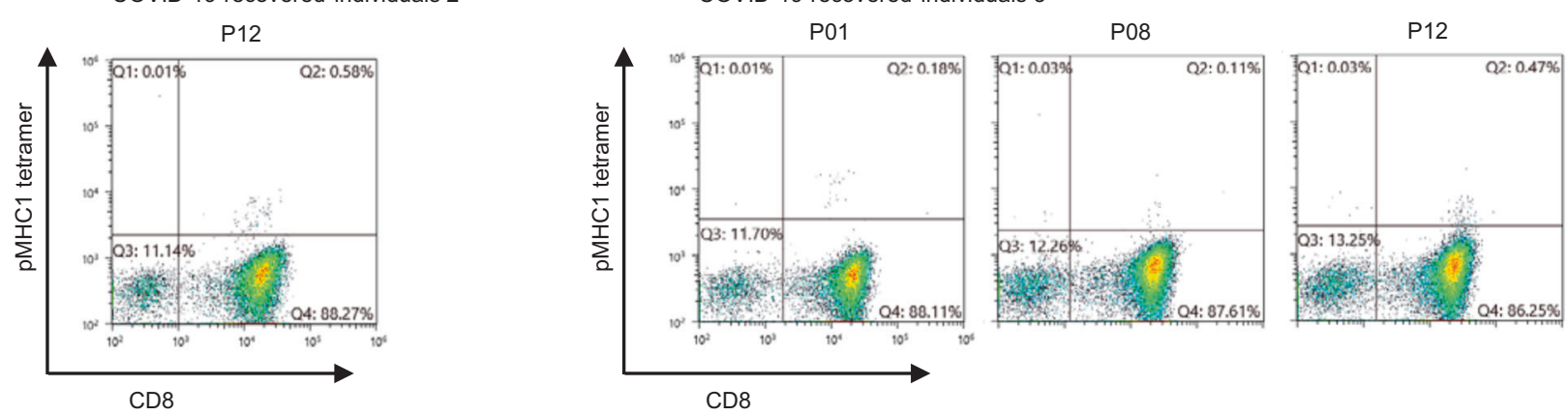

C Non-infected individuals 2
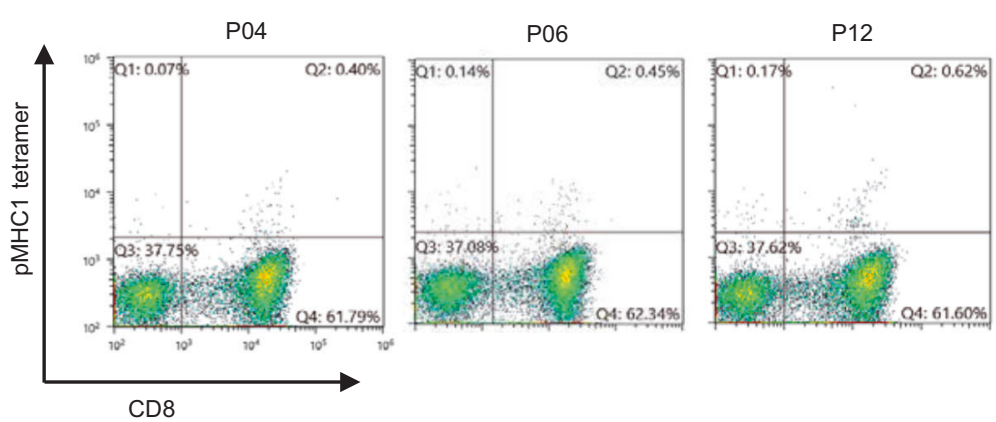

Fig. 4 Detection of $\mathrm{CD}^{+}$T cells that recognized SARS-CoV-2-derived MHC class I-binding peptides in PBMCs. A Gating strategy for detecting SARS-CoV-2-derived peptides-reactive $\mathrm{CD}^{+} \mathrm{T}$ cells. Firstly, lymphocytes population was separated by a forward scatter (FSC-A) and back scatter (BSC-A) gates. Doublets were excluded on forward scatter height (FSC-H) and forward scatter width (FSC-W). Living CD3 ${ }^{+}$CD4 ${ }^{-}$cells were selected by staining with DAPI, and expression of $\mathrm{CD} 3$ and $\mathrm{CD} 4$. pMHC1 tetramer-binding $\mathrm{CD} 8^{+}$T cells were defined by gating based on HIV control tetramer staining. B HLA-A*24:02-positive PBMCs from three COVID-19-recovered individuals were stained using pMHCI tetramers after in vitro stimulation. $\mathrm{CD}^{+} \mathrm{T}$ cells that recognize SARS-CoV-2-derived peptides were detected from every individual. C HLA-A*24:02positive PBMCs from three healthy individuals without any history of SARS-CoV-2 infection were stained using pMHCI tetramers after in vitro stimulation. Pre-existing $\mathrm{CD}^{+} \mathrm{T}$ cells that recognize SARS-CoV-2-derived peptides were detected from one of the three non-infected individuals

In this study, we have reported identification of 15 candidate vaccine peptides against COVID-19. Since T cell memories seem to be maintained in a longer period (few to several years) than antibodies and the peptides reported here are likely to avoid the influence of additional mutations that may occur in SARS-CoV-2 in the future, our peptides may enable us to provide the useful information to design the novel vaccine(s). 


\section{REFERENCES}

1. Polack FP, Thomas SJ, Kitchin N, Absalon J, Gurtman A, Lockhart S, et al. Safety and Efficacy of the BNT162b2 mRNA Covid-19 Vaccine. N. Engl J Med. 2020;383:2603-15.

2. Baden LR, El Sahly HM, Essink B, Kotloff K, Frey S, Novak R, et al. Efficacy and Safety of the mRNA-1273 SARS-CoV-2 Vaccine. N. Engl J Med. 2021;384:403-16.

3. Rambaut A, Loman N, Pybus O, Barclay W, Barrett J, Carabelli A, et al. Preliminary genomic characterisation of an emergent SARS-CoV-2 lineage in the UK defined by a novel set of spike mutations. Virological. 2020. https://virological.org/t/ preliminary-genomic-characterisation-of-an-emergent-sars-cov-2-lineage-in-theuk-defined-by-a-novel-set-of-spike-mutations/563.

4. Tegally $H$, Wilkinson $E$, Giovanetti $M$, Iranzadeh A, Fonseca V, Giandhari J, et al. Detection of a SARS-CoV-2 variant of concern in South Africa. Nature. 2021;592:438-43.

5. Network for Genomic Surveillance in South Africa (NGS-SA). SARS-CoV-2 Sequencing Update 17 December 2021. Network for Genomic Surveillance in South Africa (NGS-SA). 2021. https://www.nicd.ac.za/wp-content/uploads/2021/ 12/Update-of-SA-sequencing-data-from-GISAID-17-Dec-21_Final.pdf.

6. Faria NR, Claro IM, Candido D, Moyses Franco LA, Andrade PS, Coletti TM, et al. Genomic characterisation of an emergent SARS-CoV-2 lineage in Manaus: preliminary findings. Virological. 2020. https://virological.org/t/genomic-characterisation-of-anemergent-sars-cov-2-lineage-in-manaus-preliminary-findings/586.

7. Cherian S, Potdar V, Jadhav S, Yadav P, Gupta N, Das M, et al. Convergent evolution of SARS-CoV-2 spike mutations, L452R, E484Q and P681R, in the second wave of COVID-19 in Maharashtra, India. Microorganisms. 2021;9:1542.

8. Garcia-Beltran WF, Lam EC, St Denis K, Nitido AD, Garcia ZH, Hauser BM, et al. Multiple SARS-CoV-2 variants escape neutralization by vaccine-induced humoral immunity. Cell. 2021;184:2372-83.e9.

9. Liu Y, Liu J, Xia H, Zhang X, Fontes-Garfias CR, Swanson KA, et al. Neutralizing Activity of BNT162b2-Elicited Serum. N. Engl J Med. 2021;384:1466-8.

10. Abu-Raddad LJ, Chemaitelly H, Butt AA. Effectiveness of the BNT162b2 Covid-19 Vaccine against the B.1.1.7 and B.1.351 Variants. N. Engl J Med. 2021;385:187-9.

11. Wall EC, Wu M, Harvey R, Kelly G, Warchal S, Sawyer C, et al. Neutralising antibody activity against SARS-CoV-2 VOCs B.1.617.2 and B.1.351 by BNT162b2 vaccination. Lancet. 2021;397:2331-3.

12. Zhou D, Dejnirattisai W, Supasa P, Liu C, Mentzer AJ, Ginn HM, et al. Evidence of escape of SARS-CoV-2 variant B.1.351 from natural and vaccine-induced sera. Cell. 2021;184:2348-61.e6.

13. Zheng M, Gao Y, Wang G, Song G, Liu S, Sun D, et al. Functional exhaustion of antiviral lymphocytes in COVID-19 patients. Cell Mol Immunol. 2020;17:533-5.

14. Chen G, Wu D, Guo W, Cao Y, Huang D, Wang H, et al. Clinical and immunological features of severe and moderate coronavirus disease 2019. J Clin Investig. 2020;130:2620-9.

15. Diao B, Wang C, Tan Y, Chen X, Liu Y, Ning L, et al. Reduction and functional exhaustion of T cells in patients with coronavirus disease 2019 (COVID-19). Front Immunol. 2020;11:827.

16. Grifoni A, Weiskopf D, Ramirez SI, Mateus J, Dan JM, Moderbacher CR, et al. Targets of T cell responses to SARS-CoV-2 coronavirus in humans with COVID-19 disease and unexposed individuals. Cell. 2020;181:1489-501.e15.

17. Le Bert N, Tan AT, Kunasegaran K, Tham CYL, Hafezi M, Chia A, et al. SARS-CoV-2specific T cell immunity in cases of COVID-19 and SARS, and uninfected controls. Nature. 2020;584:457-62.

18. Peng Y, Mentzer AJ, Liu G, Yao X, Yin Z, Dong D, et al. Broad and strong memory $\mathrm{CD}^{+}{ }^{+}$and $\mathrm{CD} 8{ }^{+} \mathrm{T}$ cells induced by SARS-CoV-2 in UK convalescent individuals following COVID-19. Nat Immunol. 2020;21:1336-45.

19. Oh HL, Chia A, Chang CX, Leong HN, Ling KL, Grotenbreg GM, et al. Engineering $T$ cells specific for a dominant severe acute respiratory syndrome coronavirus CD8 T cell epitope. J Virol. 2011;85:10464-71.

20. Ng OW, Chia A, Tan AT, Jadi RS, Leong HN, Bertoletti A, et al. Memory T cell responses targeting the SARS coronavirus persist up to 11 years post-infection. Vaccine. 2016;34:2008-14

21. Kiyotani K, Park JH, Inoue $H$, Husain A, Olugbile $S$, Zewde $M$, et al. Integrated analysis of somatic mutations and immune microenvironment in malignant pleural mesothelioma. Oncoimmunology. 2017;6:e1278330.

22. Poluektov Y, George M, Daftarian P, Delcommenne MC. Assessment of SARS-CoV2 specific CD4 (+) and CD8 (+) T cell responses using MHC class I and II tetramers. Vaccine. 2021;39:2110-6.

23. Lissina A, Ladell K, Skowera A, Clement M, Edwards E, Seggewiss R, et al. Protein kinase inhibitors substantially improve the physical detection of T-cells with peptide-MHC tetramers. J Immunol Methods. 2009;340:11-24.

24. Kiyotani K, Toyoshima Y, Nemoto K, Nakamura Y. Bioinformatic prediction of potential T cell epitopes for SARS-Cov-2. J Hum Genet. 2020;65:569-75.

25. Andreatta $M$, Nielsen $M$. Gapped sequence alignment using artificial neural networks: application to the MHC class I system. Bioinformatics. 2016;32:511-7.
26. Nielsen $M$, Lundegaard C, Worning $P$, Lauemøller SL, Lamberth $K$, Buus $S$, et al. Reliable prediction of T-cell epitopes using neural networks with novel sequence representations. Protein Sci. 2003;12:1007-17.

27. Hirata J, Hosomichi K, Sakaue S, Kanai M, Nakaoka H, Ishigaki K, et al. Genetic and phenotypic landscape of the major histocompatibility complex region in the Japanese population. Nat Genet. 2019;51:470-80.

28. Sidney J, Peters B, Frahm N, Brander C, Sette A. HLA class I supertypes: a revised and updated classification. BMC Immunol. 2008;9:1.

29. van Buuren MM, Dijkgraaf FE, Linnemann C, Toebes M, Chang CX, Mok JY, et al. HLA micropolymorphisms strongly affect peptide-MHC multimer-based monitoring of antigen-specific $\mathrm{CD}^{+} \mathrm{T}$ cell responses. J Immunol. 2014; 192:641-8.

30. Yoshimura S, Tsunoda T, Osawa R, Harada M, Watanabe T, Hikichi T, et al. Identification of an HLA-A2-restricted epitope peptide derived from hypoxia-inducible protein 2 (HIG2). PLoS One. 2014;9:e85267.

31. Torikai $H$, Akatsuka $Y$, Miyauchi $H$, Terakura $S$, Onizuka $M$, Tsujimura $K$, et al. The HLA-A*0201-restricted minor histocompatibility antigen HA-1H peptide can also be presented by another HLA-A2 subtype, $A^{*} 0206$. Bone Marrow Transpl. 2007;40:165-74.

32. Arunachalam PS, Walls AC, Golden N, Atyeo C, Fischinger S, Li C, et al. Adjuvanting a subunit COVID-19 vaccine to induce protective immunity. Nature. 2021;594:253-8.

\section{ACKNOWLEDGEMENTS}

We thank K. Kiyotani at Japanese Foundation for Cancer Research for helpful discussion about prediction and selection of MHC class I-binding peptides. We thank Y. Imai, M. Koyasu, and H. Yamashita for experimental support. This study was funded by the R\&D budget of OncoTherapy Science, Inc.

\section{AUTHOR CONTRIBUTIONS}

Conceptualization: YN, TH. Investigation: M. Sakamoto, MH, M. Saito, YY, KT. Visualization: TH, M. Sakamoto, MH, M. Saito, YY, KT. Project administration: YN, TH. Supervision: YN. Writing—original draft: TH. Writing —review and editing: YN.

\section{COMPETING INTERESTS}

TH, M. Sakamoto, MH, M. Saito, YY, and KT are employees of OncoTherapy Science, Inc. YN is a stockholder and scientific advisor of OncoTherapy Science, Inc. TH and YN are listed as the inventors on pending patent application that is related to findings in this study.

\section{ADDITIONAL INFORMATION}

Supplementary information The online version contains supplementary material available at https://doi.org/10.1038/s10038-022-01013-4.

Correspondence and requests for materials should be addressed to Tetsuro Hikichi.

Reprints and permission information is available at http://www.nature.com/ reprints

Publisher's note Springer Nature remains neutral with regard to jurisdictional claims in published maps and institutional affiliations.

\footnotetext{
Open Access This article is licensed under a Creative Commons Attribution 4.0 International License, which permits use, sharing, adaptation, distribution and reproduction in any medium or format, as long as you give appropriate credit to the original author(s) and the source, provide a link to the Creative Commons license, and indicate if changes were made. The images or other third party material in this article are included in the article's Creative Commons license, unless indicated otherwise in a credit line to the material. If material is not included in the article's Creative Commons license and your intended use is not permitted by statutory regulation or exceeds the permitted use, you will need to obtain permission directly from the copyright holder. To view a copy of this license, visit http://creativecommons. org/licenses/by/4.0/.
}

(c) The Author(s) 2022 